\title{
Coaching as support for postgraduate students: A case study
}

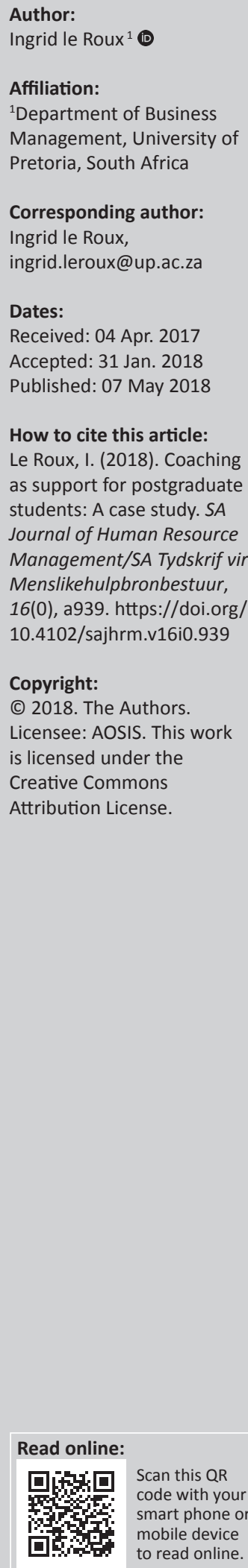

Background: Undergraduate students as a group are well researched, with focus on enhancing student engagement and improving learning and teaching methods. However, working postgraduate students have become a growing trend in the higher education sector, with little known about their experience. The purpose of this research is to better understand and to gain insight into the inter-role conflict experienced by postgraduate students owing to managing the multiple roles of work, personal life and studies. This article reports the case study of a coaching intervention administered to a group of postgraduate students over a 5-month period. The study concludes that the inclusion of a coaching intervention to assist postgraduate students in dealing with inter-role stress can no longer be ignored. Coaching support is an authentic way to support these students, with benefits reaching beyond the classroom.

Research purpose: The purpose of this research is to better understand the inter-role conflict emanating from managing work, personal life and studies, and to gain insight into the role of coaching as a support function.

Motivation for the study: There is limited research focusing on the experiences of postgraduate students, who are often working either part-time or full-time while pursuing their studies, and navigating three overlapping role domains simultaneously. Furthermore, even less is known about coaching as a support function to strike a balance between these three demanding roles.

Research design, approach and method: This study is qualitative in nature. A coaching intervention over a 5-month period was used to assist postgraduate students in managing inter-role conflict.

Main findings: The study suggests that coaching can be used as a method to address the interface between work, personal life and study demands for the working postgraduate student. To ensure successful throughput rates in the allocated time, a new support framework is required to complement the often insufficient academic interventions.

Contribution: The contribution of the research is twofold: Firstly, it focuses on working postgraduate students to gain insight into and a better understanding of the potential of coaching. Secondly, it highlights coaching as a potential support function. Very little research exists in the general literature on how to support working postgraduate students in higher education. The research also shows the potential of coaching as a support function to help postgraduate students navigate the three demanding role domains.

\section{Introduction}

There is a considerable amount of research on the challenges such as underpreparedness for class and basic academic writing skills (Shay, 2017) that undergraduate students encounter to successfully complete their studies. This is often addressed by improving teaching methods (Balan \& Metcalfe, 2012), enhancing student engagement (O'Connor, 2013) and improving academic performance through student support in order to overcome specific literacy or learning difficulties (Grant, Green \& Rynsaardt, 2010). Studies on coaching as a support approach can be found to focus on the impact of developmental coaching (Grant et al., 2010), coaching that benefits the performance of first-year students (Franklin \& Doran, 2009) and the effectiveness of coaching programmes for first-year students (Franklin \& Franklin, 2012). For example, Mühlberger and Traut-Mattausch (2015) addressed procrastination in an intervention among university students because it is perceived to be a problem associated with performance for many students.

However, less is known about the experiences of postgraduate students who are often working either part-time or full-time while pursuing their studies. The working postgraduate student has become a growing trend in the higher education sector. Yet, there has been little research to 
understand the expectations of postgraduate students who need to navigate three overlapping role domains simultaneously - work, personal life and studies. Furthermore, I wanted to know how coaching may support them in terms of the conflicts arising from their efforts to achieve balance between these three demanding roles. Thus, the purpose of this research is to better understand postgraduate student inter-role conflicts that emanate from managing these multiple roles.

The article acknowledges the belief that people engage in a multitude of social contexts owing to a strong belief that the achievement of multiple roles may enhance individual wellbeing (Pluut, 2015). The researcher comes from an interpretivist paradigm and believes that multiple social realities exist rather than only one truth. Reality is therefore subjective and depends on the experience, perception, social context and interaction between the individual and the researcher. The aim is to gain an insight into and a better understanding of the realities of working postgraduate students in order to make recommendations on the support needed to successfully balance the multiple roles of work, personal life and studies. The article reports a case study of a coaching support intervention that was administered to a group of working postgraduate students over a period of 5 months. The case provides better insight into the role conflict experienced among the three domains. It also informed a better understanding of how coaching as a support function can minimise the different types of role conflict.

The contribution of the research is twofold: Firstly, it highlights the neglected group of postgraduate students in the general literature in higher education. Secondly, it demonstrates the potential of coaching as a support function to help postgraduate students navigate the three demanding role domains. The findings suggest (for this group) that a great deal more support is needed than just academic interventions. To ensure a successful throughput rate in the allocated time, a new support framework is required. Coaching is a method that can be used to address the interface between work, personal life and study demands which are much greater for working postgraduate students.

The article is structured as follows: I firstly began by examining the relevant constructs. Then, I focused on the research design and illustrated the sample and data collection procedure. This was followed by a discussion of the findings as well as an overview of the practical implications and limitations of the study.

\section{Literature review on role and conflict theory}

The domain of work-family conflict is fast growing, with many studies examining the relationship between work and family conflict and several potential consequences (Amstad et al., 2011; Pluut, 2015). Work provides the means to take care of our families and ourselves and is of great importance for individuals and societies. However, work can also be stressful and work-induced strain is often taken home (Pluut, 2015). Juggling between work and family roles has become part of the everyday routine for individuals in many professions. The perceived imbalance between the demands of work and the demands of family life presents a complex phenomenon also referred to as the time-bind (Hochschild, 1997, in Tausig \& Fenwick, 2001). This is reflected in simultaneous time and energy demands of the workplace and family life, both of which are considered to be greedy institutions (Tausig \& Fenwick, 2001). The opposite of timebind, or a lack of time in meeting both the demands of work and family life, is a sense of work-life balance. The notion stems from the changing nature of work and families, relating to longer work hours and a lack of flexible schedules (Tausig \& Fenwick, 2001). Role theory provides us with a lens to look at the above imbalance.

Role theory is rooted in sociology and social psychology, and its basic tenets can be explained through concepts such as role, social position and expectation (Biddle, 1986; Pluut, 2015). Conflict theory and role theory are often used as interchangeable frameworks. For the purpose of this study, role theory refers to a set of socially acceptable roles relating to work, spouse, parent, member, friend or student, resulting in the two concepts of conflict and overload. Inter-role conflict is seen as the result of incompatible demands or an overload of demands owing to the multiple roles that people need to fulfil. Strain, feelings of work overload and inter-role conflict can present themselves if any competing demands are made on the roles that are simultaneously balanced by an individual (Pluut, 2015). Inter-role conflict can interfere with both the work role and the family role, thus creating a two-way interference. Work-family conflict is considered to have a potential for stress and may have a negative effect on the well-being and behaviour of individuals (Amstad et al., 2011).

The composition of the workforce has changed dramatically in recent decades (Eby et al., 2005), with many employees doing postgraduate studies to enable them to stay ahead in the intensely competitive global job market. This results in an additional domain to manage simultaneously with that of work and personal life. For postgraduate students, their role set therefore also includes studies as a third domain that may influence the already strained situation of work and personal life. The third domain may further complicate and add to the potential interrole conflict as well as contribute to the role overload.

This study uses role theory and inter-role conflict theory to explain the cross-domain relationships that exist because of the three roles that postgraduate students need to balance.

For the purpose of this study, the role set comprises work, personal life and study, resulting in increased inter-role conflict. Working or work is seen as an individual pursuing a career, working to support themselves financially on a fulltime or part-time basis. Because of the age group of the respondents (see sample description), and the fact that they are not married, do not have children and do not live with or look after family members, the focus is on the personal life role, which also includes social life, instead of the family 
life role. The focus of this study is on the different roles that postgraduate students play, balancing the roles of work, personal life and studies.

\section{Coaching as a method of support for postgraduate students}

The demand for coaching and interest in coaching research has increased over the last two decades (Grant, 2011; Mühlberger \& Traut-Mattausch, 2015; Theeboom, Beersma \& Van Vianen, 2014). Previous research examining the impact of coaching indicates that coaching in general has a positive impact on several individual and organisational outcomes such as academic performance and goal attainment, as well as well-being (Mühlberger \& Traut-Mattausch, 2015).

\section{Coaching}

The coaching process is described as a solution-focused, systematic process that supports reflective learning (Mühlberger \& Traut-Mattausch, 2015). Coaching as a construct is defined as a professional, collaborative and outcomes-driven method of learning that seeks to develop an individual and raise self-awareness so that specific goals might be achieved at a more effective level (COMENSA, 2016). Coaching aims to foster the ongoing performance, selfdirected learning and personal growth of the client (Grant \& O'Connor, 2010; Stober \& Grant, 2006). Coaching for the purpose of this study is seen as a personal or situational factor that aims to reduce inter-role conflict.

Coaching relationships inherently provide the opportunity to interact with a client on more than one level of engagement, namely, on a cognitive, behavioural and emotional level. This 'helping process' provides a context where learning can take place (Parker et al., 2015). Trust between the coach and the client is of utmost importance and emerging literature on coaching has now begun to recognise trust as one of the crucial elements for an effective coaching relationship (Kim \& Kuo, 2015). In this study, trust refers to 'the willingness of a party to be vulnerable to the action of another party' and is based on individuals' expectations that other people will behave in certain ways that are helpful and supportive (Mayer, Davis \& Schoorman, 1995:172 as cited by Kim \& Kuo, 2015). However, the crucial ability of a coach to lead the client through the coaching process in order to promote the client achieving their goals is of utmost importance (Mühlberger \& Traut-Mattausch, 2015). Therefore, the aim is ultimately to gain insight and a better understanding of the people (postgraduate students) that are the focus of this study.

Based on the above overview, the following two research questions were formalised:

- What are the relationships between work, personal life and study as role conflict?

- Can coaching as a support function reduce the level of inter-role conflict experienced?

\section{Research method}

The purpose of the study was to explore the potential contribution of coaching support to working postgraduate students. The research specifically aims to gain insight and a better understanding of the inter-role conflict students experience and the role of coaching as a support function. This is in line with an interpretivist paradigm to understand human behaviour (Babbie \& Mouton, 2014).

\section{Research approach}

The study followed a qualitative inductive methodology approach using structured dyadic coaching sessions to understand and make sense of the experiences of postgraduate students in achieving a balance in their work, personal life and studies. The primary goal of the research was to describe and understand human behaviour rather than to explain human behaviour (Babbie \& Mouton, 2014).

\section{Research design}

In an attempt to achieve the aims and objectives of this study, a case study design was used to understand the coaching experience. According to Stake $(1995,2005)$, case studies are understood as an in-depth study of how people experience a particular situation or phenomenon. A free coaching intervention was offered to support students in dealing with the multiple roles they may experience. The sample consisted of 10 postgraduate university students purposefully recruited from the students enrolled for honours or master's degrees in Business Management. The description of the sample is five males and five females: four of mixed race and six Caucasians. The nationalities of the sample included those from Uganda (1), Tanzania (1), Mozambique (1) and South Africa (7). An open invitation was communicated to all students $(N=35)$ enrolled during their first contact session. The lecturer invited the students to take part in a coaching intervention for a 5 -month period. The only brief provided to the students was that coaching is widely used in organisations to support employees. Eleven students decided to take part voluntarily in the coaching intervention. One of the students dropped out owing to the work overload as a full-time employee. A unique feature of the sample was that none of the subjects were married, had children or needed to financially support any other individual. The ages of the respondents varied between 22 and 26 years.

The study design has two layers: to better understand the inter-role conflict experienced; and to gain insight into coaching as a support function for working postgraduate students.

Coaching is increasingly seen as a mode to enhance performance, development and well-being, and effective questioning lies at the heart of the coaching conversation. The result of effective questioning is analysing problems and exploring unhelpful thinking patterns (Grant \& O'Connor, 2010). The intervention took place over a 5-month period. 
The duration of the sessions was between $1 \mathrm{~h}$ and $1.5 \mathrm{~h}$, depending on the specific need of the student. Five coaching sessions per student were administered. Thus, the data for analysing student-work life demands were drawn from 50 coaching sessions.

\section{Data collection}

Each student who had volunteered to be part of the coaching intervention was asked to hand in a written document that answered the following question: 'What do you expect from the coaching sessions?' No guidelines were given. A second report written after the completion of all the sessions asked students to reflect on the following open-ended question: 'Reflect on your experience of taking part in the intervention'. Again, no guidelines were given to avoid any bias. The coach made observational notes during each session, which also formed part of the data collected. The respondents gave ethical consent and agreed that the data collected could be used.

\section{Data analysis}

The analysis process began by a careful reading of the students' pre-coaching and post-coaching written reports as well as reflecting on the observational notes. The data were analysed using an inductive approach. The written responses to both the pre-coaching expectations and post-coaching reflections were captured on a spreadsheet which was analysed through first-order coding, followed by secondorder coding where the data were collated into three role domain categories (work, personal life and studies as well as a new emerging category labelled 'managing role overlaps').

\section{Trustworthiness and transparency}

The coding process and the resulting themes were shared with two independent academic colleagues. Based on their reviews, some refinements were made on the second-order categories. The findings were further discussed by conducting member checking with a smaller group of the participants in the coaching sessions, who agreed with the interpretation with minor additions.

\section{Findings}

This section of the article reports on participants' responses before and reflections after the support intervention, as well as notes from the coach as the observer.

\section{Expectations}

Findings derived from respondents' expectations follow: The themes resulting from the coding could be linked to role theory as well as to inter-role conflict theory. The expectations before starting the coaching support process could be categorised into three domain roles: work, personal life and studies. Data also emerged that were categorised as 'managing role overlaps'. No dominant domain emerged from the reports on what was expected from the coaching support intervention. An equal distribution between the domains and managing the role overlaps was reported. The work responses varied from issues such as handling stress and functioning in a team to advice on handling management at work and time management at work. The personal life expectations varied from managing students' personal lives better and dealing with stress and change to building confidence and controling their lives. The study expectations varied from support in managing the transition to a student and emotional support to time management for sufficient study and support in clarifying study goals. Managing the role overlaps received one response more than the other three categories, respectively, and focused on finding balance, managing all roles and gathering support to deal with added responsibilities owing to the many roles. The data suggest that participants felt equally consumed by the work, personal life and study roles, expressing a need for support to find a balance in managing all three simultaneously. The coaching support expected was perceived as an aid to help build confidence, grow as a person and cope with additional stress, time management and decision-making.

The following section reports on the reflections after the completion of the support intervention: The categories derived from the coding could again be linked to role theory with its tenets, namely, conflict and overload. The reflections after the coaching support intervention confirmed the three domain roles, namely, work, personal life and studies. Data categorised as managing role overlaps were also present. However, unlike in the expectations findings, a clearly dominant role domain, namely, personal life, emerged from the reflections. This constituted $70 \%$ of the written feedback. Within the personal life domain, two sub-categories emerged: 'self' and 'relationship issues'.

The sub-category self constituted approximately $80 \%$ of the feedback in the personal life domain. The following is a short summary of anecdotes that were reported:

'Coaching helped me realise I can achieve my goals; the session made me feel excited and a sense of relief to speak about things hampering my progress.'

'It helped me deal with pressures, helped me to feel more relaxed and deal with stress.'

'It helped me realise that I do not have any "me" time, helped me to believe in myself, helped me to focus on what is important, time management, goal-setting, to prioritise.'

The data suggest that participants felt consumed by the work and student roles to the extent of feeling a loss of self. Related to this was a sense of being out of control. The findings are in line with Pluut (2015), who argues that juggling social roles in multiple domains can become overly demanding and stressful in such a way that a person's psychological wellbeing is affected. Amstad et al. (2011) postulate that the interests in the challenges taking place in the economic environment is not likely to fade and suggest the trend will continue in the coming years. The coaching sessions were perceived as supporting participants to identify strategies for 
regaining some sense of being in control by setting goals, prioritising and managing time. As one student said:

'The sessions helped me feel more relaxed about things I cannot control, and helped me to focus on what was really important at that specific moment.'

The sub-category relationships constituted $20 \%$ of the feedback on the personal life domain. Pluut (2015) mentioned that although work and family dominate a large part of our lives, the role of family member and employee are not prominent social roles for young adults. Instead, social life roles become prominent but often conflicting in late adolescence. The following is a short summary of what was reported by participants:

'It was good talking to somebody about the stress between me and my boyfriend; thanks to the sessions I ended a 6-year relationship that did not encourage what I want from life; my relationship was strained due to the extra pressure of studies and talking about it helped; the sessions helped me through a grieving process after the end of a 3-year relationship.'

The data suggest that participants felt overwhelmed and lost when relationships went wrong. Related to this was a sense of being out of control. The coaching sessions appeared to help participants deal with emotions and separate their work, personal life and study roles. It is therefore important to note the need for studying social study conflict when studying the well-being of students, specifically that of postgraduate students who need to balance work-personal life and study roles simultaneously. As one student reported:

'I almost derailed and lost focus after the break-up (6 years), but the coaching sessions helped me to separate my emotions from what is needed to complete my studies and function at work.'

The second category that emerged from the reflections was that of work, which also constitutes $10 \%$ of the overall feedback. The following is a short summary of what was reported:

'I could discuss work-related problems which hampered my progress and caused additional stress.'

'I felt supported through all the stressful times when my work and study loads increased; talking about interpersonal problem experienced at work.'

'It helped me to sharpen my problem-solving skills.'

The data suggest that participants felt supported when they experienced increased work commitments as well as interpersonal problems at work. Strategies that foster a family/relationship-friendly working environment are therefore likely to result in benefits for both the organisation as well as the employee (Amstad et al., 2011). The coaching sessions appeared to help participants to better deal with challenges and issues at work. One student reported:

'The session helped me to see the bigger picture and not only focus on issues at work.'

The third category that emerged from the reflections was that of studies, which also constituted $10 \%$ of the overall feedback. The following is a short summary of what was reported:
'The sessions made me feel more relaxed about balancing studies and work pressures; helped me to plan better for assessments; helped me to accept the outcome of a test I failed and to plan ahead; the sessions helped me to realise I was not defined by the marks received in my study.'

The data suggest that participants perceived the sessions as beneficial to them in study-related matters such as dealing with marks and planning for assessments. One student reported:

'The sessions helped me to structure, set goals and prioritise what needs to be done to complete my studies successfully.'

The fourth category that emerged from the reflections was that of managing the different role overlaps, which also constituted $10 \%$ of the overall feedback. The following is a short summary of what was reported:

'The sessions helped me to realise that I have attained good time management habits to balance all I have to do; the sessions helped me to balance the different roles I have to play; doing a work-life activity helped me to balance studies with what was already on my plate; the sessions helped me to set specific goals not only for studies and work but also my life.'

The data suggest that participants experienced the coaching support as beneficial in managing the three roles. It helped them to create a work-personal, life-study balance and to minimise stress. The inter-role conflict created an imbalance that can take three directions and is seen as a potential source of stress, well-being and burnout (Amstad et al., 2011). Developing goals and strategies to find a balance was perceived as an outcome of the coaching support. One student reported:

'The sessions helped me to develop a better understanding of the roles I have to manage and find a better balance between my studies, personal life and work.'

According to the findings, the inter-role conflict in a workpersonal, life-study relationship can take three directions. However, coaching support was perceived as a positive experience and an enabler to assist participants in dealing with many issues, such as time management, managing change, setting goals and prioritising, and meeting relationship demands in spite of the other two roles students' needed to balance.

Coaching as a method to extract the data served the research well. Writing their own expectations and reflections allowed the subjects to voice their apprehensions and experiences without bias. As the researcher and facilitator of the coaching process, I also made observations that contribute to the credibility and resonate with the role and inter-role conflict theory. Initially, the participants looked uncomfortable to speak about personal issues and it took time to build a trust relationship between the coach and the client. However, the reflections reported a positive working relationship, showing a working alliance that developed in the process of the support relationship. This is in line with Lai and McDowall (2014) who postulated that a coach's attributes have a significant influence on the effectiveness of the coaching process and results. The participants reported:

'I appreciated the opportunity to have somebody who really cared about what is going on in my life.' 
'I discussed things in the sessions I have never discussed with anyone before.'

'Speaking to my coach made me realise I am doing okay.'

'I appreciated the opportunity to speak freely.'

'I felt comfortable to discuss private things in the session.'

As one student said:

'I felt more relaxed after each session and experienced the coach as somebody who really listens.'

Over the five sessions, the participants revealed more and became more forthcoming as a result of the trust relationship that developed over time. This is in line with Gessnitzer and Kauffeld (2015) who argued that a working alliance develops in the process of all helping relationships and consists of a mutual agreement about goals and tasks needed to be achieved as well as the bond between the coach and the client.

The findings provide support for the existence of interrelationships as well as potential benefits from coaching as an intervention.

\section{Discussion \\ Outline of the results}

The overall results provide confirmation of the inter-role conflict theory, particularly the effects of role overload and role overlap on individuals. The study highlights the apparent incompatibility of study, social or personal life and work roles if not supported by one or other intervention. The value of the coaching support lies not in offering participants specific solutions but a dyadic conversation that fosters selfreflection and problem-solving. From the students' reports, the coaching sessions had a dramatic effect on their wellbeing. While the results suggest a strong effect for the coaching intervention on the 'self' or individual, there was a positive effect on the work and study roles, as well as embracing strategies to manage the different roles. Therefore, cross-domain effects are not only negative but can also potentially be positive, as was experienced by the students in this study. The results provide a strong indication that if the personal life of the individuals, specifically the 'self', is balanced, it would have a effect in minimising the conflict experienced in the other domains (see Figure 1).

\section{Practical implications}

The results of this research have implications for universities as well as organisations that have employees pursuing studies. For academic institutions, the results signal the importance of providing postgraduate students with support to reduce personal life stressors and conflicts. Most supervisors are neither equipped nor comfortable with engaging students on such issues. Supervisors can provide instrumental assistance with respect to academic success, whereas coaching can provide a platform for socio-emotional coping to help

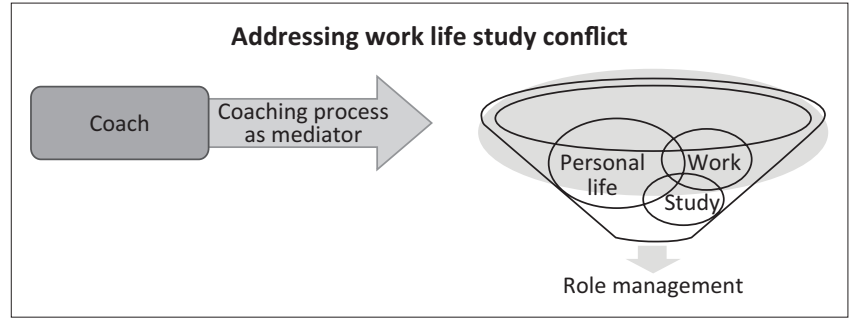

FIGURE 1: Framework for personal life as a mediator for study and work domains.

postgraduate students to balance and navigate concurrent student-work life role demands. The second implication is for companies and employers: financial and leave support is not enough; in addition to bursaries, employers might consider whether providing employees engaged in studies with coaching support may lessen work stress and improve work performance.

\section{Limitations and recommendations}

There is no research without limitations and it is the same in this study. However, its limitations give direction to suggestions for future research. Firsrly, the composition of the current sample (eight part-time employed students and only two full-time employed students) suggests that researchers should be thoughtful about choosing their sample to represent a more even distribution. Of course, the sample size and diversity (i.e. married vs. single, children and the impact of age) should be increased to improve generalisability of findings. Finally, a comparison between undergraduate and postgraduate students would help to determine whether differences exist in inter-role conflict and consequently whether there is a need for different interventions for each group.

\section{Conclusion}

Figure 1 provides a visual framework of the dominant role of personal life compared to the work and study domains. The coaching intervention addressed the personal life domain, resulting in less conflict being experienced in the work and study domains.

The results of the coaching intervention suggest that coaching has a bigger effect on personal life than on the other two domains. This confirms the interrelationships that exist between personal life, work and studies. If the 'self' is in control, then one feels supported or in balance. This in turn has a direct relationship with the degree of stress experienced in the work and study domains. The more the individual feels balanced, the better they deal with the other domains.

Working postgraduate students experience inter-role conflict between studies, personal life and work. To manage the three domains, different interventions other than just academic support are required. Furthermore, institutions need to understand how to better support such students to improve timely throughput. Coaching is one such way to support 
postgraduate students in inter-role conflict. This particular study demonstrated coaching interventions that empower students, which has a direct effect on assisting them in managing inter-role conflict in the work and study domains through addressing personal life issues.

The study concludes that the inclusion of a coaching intervention as a support function to assist postgraduate students in dealing with inter-role stress can no longer be ignored. Coaching support is an authentic way to support postgraduate students and leads to rich and robust learning about the self and other issues to be managed, giving a better understanding and serving graduates long after leaving higher education institutions. The benefit added by coaching support thus extends far beyond the higher education classroom. In the words of a student:

'The sessions were important to me, helping me to focus on my goals and not that of other people. I felt supported through all the stressful times when my work and study load increased. The sessions helped me to find balance between life, work and studies.'

\section{Acknowledgements \\ Competing interests}

The author declares that she has no financial or personal relationships that may have inappropriately influenced her in writing this article.

\section{References}

Amstad, F.T., Meier, L.L., Fasel, U., Elfering, A. \& Semmer, N.K. (2011). A meta-analysis of work-family conflict and various outcomes with a special emphasis on cross domain versus matching-domain relationships. Journal of Occupational Health Psychology 16(2), 151-169. https://doi.org/10.1037/a0022170

Babbie, E., \& Mouton, J. (2014). The practice of social research. Oxford University Press Southern Africa: Cape Town.

Balan, P., \& Metcalfe, M. (2012). Identifying teaching methods that engage entrepreneurship students. Education \& Training 54(5), 368-384. https://doi. org/10.1108/00400911211244678

Biddle, B.J. (1986). Recent developments in role theory. Annual Review of Sociology 12, 4-92. https://doi.org/10.1146/annurev.so.12.080186.000435

Coaching and Mentoring South Africa (COMENSA) (2016). COMENSA Coaching. Retrieved from: http://www.comensa.org.za/information/coaching
Eby, L.T., Casper, W.J., Lockwood, A., Bordeaux, C., \& Brinley, A. (2005). Work and family research in 10/OB: Content analysis and review of the literature (19802002). Journal of Vocational Behaviour 66(1), 124-197. https://doi.org/10.1016/j. jvb.2003.11.003

Franklin, J., \& Doran, J. (2009). Does all coaching enhance objective performance independently evaluated by blind assessors? The importance of the coaching model and content. International Psychology Review 4(2), 128-245.

Franklin, J., \& Franklin, A. (2012). The long-. A controlled 18 months follow up of two methods, term independently assessed benefits of coaching. International Coaching Psychology Review 7(1), 33-38.

Gessnitzer, S., \& Kauffeld, S. (2015). The working alliance in coaching: Why behaviour is key to success', Journal of Applied Behavioural Science 5(2), 177-197. https:// doi.org/10.1177/0021886315576407

Grant, A.M., (2011), Workplace, executive and life coaching: An annotated bibliography from the behavioural science and business literature (1st Jan 2011), Coaching Psychology Unit. Australia: University of Sydney.

Grant, A.M., Green, L.S., \& Rynsaardt, J. (2010). Developing coaching for high school teachers: Executive coaching goes to school. Coaching Psychology Journal: Practice and Research 62(3), 151-168.

Grant, A.M., \& O'Connor, S.A. (2010). The differential effects of solution-focused and problem-focused coaching questions: A pilot study with implications for practice. Industrial and Commercial Training 42(2), 102-111. https://doi.org/10.1108/ 00197851011026090

Kim, S., \& Kuo, M.H. (2015). Examining the relationship among coaching, trustworthiness and role behaviour: A social perspective. Journal of Applied Behavioural Science 5(2), 152-176.

Lai, Y.L., \& McDowall, A. (2014). A systematic review (SR) of coaching psychology: Focusing on the attributes of effective coaching psychologists. International Coaching Psychology Review 9(2), 118-134.

Mühlberger, M.D., \& Traut-Mattausch, E. (2015). Leading to effectiveness: Comparing dyadic coaching and group coaching. Journal of Applied Behavioural Science 5(2), 198-230. https://doi.org/10.1177/0021886315574331

O'Connor, K.J. (2013). Class participation: Promoting in-class student engagement. Education 133(3), 340-345.

Parker, P., Wasserman, I., Kram K.E., \& Hall, D.T. (2015). A relational communication approach to peer coaching. Journal of Applied Behavioural Science 51(2), 231-252. https://doi.org/10.1177/0021886315573270

Pluut, H. (2015). A balanced examination of inter-role conflict. Doctoral thesis, Tilburg University, Netherlands, pp. 1-147.

Shay, S. (2017). Education investment towards the ideal future: South Africa's strategic choices. South African Journal of Science 113(1-2), 1-10. https://doi.org/ $10.17159 /$ sajs.2017/20160227

Stake, R.E. (1995). The art of case study research. Thousand Oaks, CA: Sage.

Stake, R.E. (2005). Qualitative case studies. In N.K. Denzin \& Y.S. Lincoln (eds.), The SAGE handbook of qualitative research (3rd ed.) (pp. 443-466). Thousand Oaks, CA: Sage.

Stober, D.R., \& Grant, A.M. (2006). Towards a conceptual approach to coaching models. In D.R. Stober \& A.M. Grant (eds.), Evidence based coaching handbook, (pp. 355-366). Wiley, New York: Wiley.

Tausig, M., \& Fenwick, R. (2001). Unbinding time: Alternate work schedules and worklife balance. Journal of Family and Economic Issues 22(2), 101-119. https://doi. org/10.1023/A:1016626028720

Theeboom, T., Beersma, B., \& Van Vianen, A. (2014). Does coaching work? A metaanalysis on the effects of coaching on individual level outcomes in an organisational context. Journal of Positive Psychology 9(1), 1-18. https://doi.org/10.1080/17439 760.2013 .837499 